\title{
Sites of metastasis and overall survival in esophageal cancer: a population-based study
}

This article was published in the following Dove Press journal:

Cancer Management and Research

\author{
San-Gang Wu, I,* Wen-Wen \\ Zhang, ${ }^{2,}$ 'Zhen-Yu He, ${ }^{2}$ \\ Jia-Yuan Sun, ${ }^{2}$ Yong-Xiong \\ Chen, ${ }^{3}$ Ling Guo ${ }^{4}$ \\ 'Department of Radiation Oncology, \\ Xiamen Cancer Hospital, The First \\ Affiliated Hospital of Xiamen University, \\ Xiamen, ${ }^{2}$ Department of Radiation \\ Oncology, Sun Yat-Sen University \\ Cancer Center, State Key Laboratory of \\ Oncology in South China, Collaborative \\ Innovation Center of Cancer Medicine, \\ Guangzhou, ${ }^{3}$ Eye Institute of Xiamen \\ University, Fujian Provincial Key \\ Laboratory of Ophthalmology and \\ Visual Science, Medical College, Xiamen \\ University, Xiamen, ${ }^{4}$ Department of \\ Nasopharyngeal Carcinoma, Sun Yat-Sen \\ University Cancer Center, State Key \\ Laboratory of Oncology in South China, \\ Collaborative Innovation Center of \\ Cancer Medicine, Guangzhou, People's \\ Republic of China \\ *These authors contributed equally to \\ this work.
}

Background: There are few population-based studies of the sites of distant metastasis (DM) and survival from esophageal cancer (EC). The aim of this study was to assess the patterns and survival outcomes for site-specific DM from EC using a population-based approach.

Methods: Patients diagnosed with de novo stage IV EC between 2010 and 2014 were identified from the Surveillance, Epidemiology, and End Results program database. Overall survival (OS) was compared according to the site of DM.

Results: We included 3218 patients in this study; the most common site of DM was the liver, followed by distant lymph nodes, lung, bone and brain. Median OS for patients with liver, distant lymph node, lung, bone, and brain metastases was 5, 10, 6, 4, and 6 months, respectively $(p<0.001)$. Site and number of distant metastases were independent prognostic factors for OS. In patients with a single site of DM, using liver metastases as reference, OS was lower for bone metastases $(p=0.026)$ and higher for distant lymph node metastases $(p=0.008)$, while brain ( $p=0.653$ ) or lung $(p=0.081)$ metastases had similar OS compared with liver metastases. Similar site-specific survival differences were observed in the subgroup with esophageal adenocarcinoma. However, distant lymph node metastases was associated with better survival $(p=0.002)$ compared to liver, bone, or lung metastases in esophageal squamous cell carcinoma.

Conclusion: Site of metastasis affects survival in metastatic EC; OS was worst for bone metastases and greatest for distant lymph node metastases.

Keywords: esophageal cancer, SEER, bone metastases, liver metastases, lung metastases, brain metastases

\section{Introduction}

Metastasis to distant organs is the leading cause of cancer-related deaths. ${ }^{1-4}$ Esophageal cancer (EC) is a highly lethal malignant tumor. The incidence of EC, especially the rate of esophageal adenocarcinoma (AC) in Western countries has gradually increased in recent decades..$^{5-7}$ Approximately $50 \%$ of patients present with metastases to distant lymph nodes or organs at initial diagnosis. ${ }^{8,9}$ The prognosis of metastatic EC is poor, and the five-year survival rate is less than $5 \% .^{10,11}$ Although the major mechanisms that regulate metastasis have been identified, limited advances have been made in our understanding of the epidemiology of cancer metastasis.

EC most commonly spreads to the liver, followed by lung, bone, and brain. ${ }^{12-15}$ Therefore, knowledge of the patterns of distant metastasis (DM) is crucial to improve patient treatment and follow-up. Population-based cancer registries provide an excellent opportunity to investigate the relationship between the patterns of DM and prognosis in metastatic cancer. However, such data are rarely recorded. The purpose of this study was to assess the site-specific patterns of DM and survival outcomes of metastatic EC using the surveillance, epidemiology, and end results (SEER) database. 


\section{Methods}

Data were obtained from the recent SEER-18 database, which is maintained by the National Cancer Institute and represents approximately $28 \%$ of the population of the United States. ${ }^{16}$ We limited this study to patients diagnosed between 2010 and 2014 as detailed information about site-specific metastasis was not recorded before 2010. We identified patients with de novo stage IV esophageal squamous cell carcinoma (SCC) or AC. Patients for whom EC was not the first tumor or for whom data on sites of DM were not available were excluded. Approval for this study was obtained from the Institutional Review Board of the First Affiliated Hospital of Xiamen University.

We assessed the effect of potential demographic and clinicopathological variables (age, sex, race/ethnicity, tumor location, histological subtype, tumor grade, tumor classification, nodal classification, treatment, and sites and the number of DM) on patient survival. The sites of DM were classified as distant lymph node, bone, brain, liver, and lung. Due to the moderate sensitivity and high specificity of the radiotherapy and chemotherapy data, radiotherapy and chemotherapy are classified as "yes" or "no/unknown" in the current SEER custom database. ${ }^{17}$ Survival time from initial diagnosis (months), specific cause of death, and vital status were also extracted from the dataset. The primary end point of this study was overall survival (OS).

Independent predictors of OS in de novo stage IV EC were assessed using a Cox proportional model. Kaplan-Meier analysis and log-rank testing were used to compare OS. $p<0.05$ was considered statistically significant. All calculations were performed using SPSS statistical software (version 21.0; IBM Corporation, Armonk, NY, USA).

\section{Results}

\section{Characteristics of the patients}

A total of 3218 patients with de novo stage IV EC were included. DM was diagnosed by pathological examination in 950 patients $(29.5 \%)$ and clinical methods in 2268 patients $(70.5 \%)$. Table 1 summarizes the demographic and clinicopathological characteristics of the 3218 patients; 2931 (91.1\%) patients were aged $\geq 50$ years, $2706(84.1 \%)$ were males, 2703 (84.0\%) were White, 2065 (64.2\%) had tumors located in the lower third of the esophagus, $2357(73.2 \%)$ had AC, and 2122 (65.9\%) had node-positive disease.

\section{Sites of distant metastases}

A total of 5024 sites of DM were identified in the 3218 patients with de novo stage IV EC. The liver was the most common site of DM $(1678,33.4 \%)$, followed by distant (non-regional) lymph nodes $(1334,26.6 \%)$, lung (1028, $20.5 \%)$, bone (791, 15.7\%), and brain (193, 3.8\%). Overall, 1885 (58.6\%) patients had DM to a single organ. The distributions of the sites of DM are shown in Table 2.

\section{Treatment}

Overall, 55/3218 (1.7\%) patients underwent esophagectomy, 1319 (41.0\%) received radiotherapy, 1899 (59.0\%)

Table I Characteristics of the 3218 patients with stage IV esophageal cancer

\begin{tabular}{|c|c|}
\hline Variable & $\mathbf{n}$ \\
\hline \multicolumn{2}{|l|}{ Age (years) } \\
\hline$<50$ & 287 \\
\hline$\geq 50$ & 2931 \\
\hline \multicolumn{2}{|l|}{ Sex } \\
\hline Male & 2706 \\
\hline Female & 512 \\
\hline \multicolumn{2}{|l|}{ Race/ethnicity } \\
\hline White & 2703 \\
\hline Black & 335 \\
\hline Other/unknown & 180 \\
\hline \multicolumn{2}{|l|}{ Tumor location } \\
\hline Upper third & 126 \\
\hline Middle third & 371 \\
\hline Lower third & 2065 \\
\hline Overlapping lesion & 195 \\
\hline Unknown & 461 \\
\hline \multicolumn{2}{|l|}{ Histology } \\
\hline $\operatorname{scc}$ & 861 \\
\hline$A C$ & 2357 \\
\hline \multicolumn{2}{|l|}{ Grade } \\
\hline GI & 74 \\
\hline G2 & 962 \\
\hline G3-4 & 1606 \\
\hline Unknown & 576 \\
\hline \multicolumn{2}{|l|}{ Tumor classification } \\
\hline $\mathrm{TI}$ & 735 \\
\hline T2 & 139 \\
\hline T3 & 576 \\
\hline T4 & 544 \\
\hline Unknown & 1224 \\
\hline \multicolumn{2}{|l|}{ Nodal classification } \\
\hline No & 743 \\
\hline $\mathrm{NI}$ & 2122 \\
\hline Unknown & 353 \\
\hline \multicolumn{2}{|l|}{ Surgery } \\
\hline No & 3163 \\
\hline Yes & 55 \\
\hline \multicolumn{2}{|l|}{ Radiotherapy } \\
\hline No/unknown & 1899 \\
\hline Yes & 1319 \\
\hline \multicolumn{2}{|l|}{ Chemotherapy } \\
\hline No/unknown & 1190 \\
\hline Yes & 2028 \\
\hline
\end{tabular}

Abbreviations: AC, adenocarcinoma; GI, well differentiated; G2, moderately differentiated; G3, poorly differentiated; G4, undifferentiated; N, node; SCC, squamous cell carcinoma; T, tumor. 
Table 2 Patterns of distant metastases for the 3218 patients with stage IV esophageal cancer

\begin{tabular}{|c|c|}
\hline Sites of distant metastases & $\mathbf{n}$ \\
\hline \multicolumn{2}{|l|}{ One site of distant metastasis } \\
\hline Distant lymph node & 544 \\
\hline Bone & 278 \\
\hline Brain & 56 \\
\hline Liver & 702 \\
\hline Lung & 305 \\
\hline \multicolumn{2}{|l|}{ Two sites of distant metastasis } \\
\hline Distant lymph node + bone & 88 \\
\hline Distant lymph node + brain & 18 \\
\hline Distant lymph node + liver & 260 \\
\hline Distant lymph node + lung & 117 \\
\hline Bone + brain & 22 \\
\hline Bone + liver & 118 \\
\hline Bone + lung & 51 \\
\hline Brain + liver & 20 \\
\hline Brain + lung & 9 \\
\hline Liver + lung & 233 \\
\hline \multicolumn{2}{|l|}{ Three sites of distant metastases } \\
\hline Distant lymph node + bone + liver & 62 \\
\hline Distant lymph node + bone + lung & 32 \\
\hline Distant lymph node + liver + lung & 142 \\
\hline Distant lymph node + bone + brain & 5 \\
\hline Distant lymph node + brain + liver & 2 \\
\hline Distant lymph node + brain + lung & 3 \\
\hline Bone + liver+ lung & 52 \\
\hline Bone + brain+ liver & 10 \\
\hline Bone + brain+ lung & 6 \\
\hline Brain + liver + lung & 12 \\
\hline \multicolumn{2}{|l|}{ Four sites of distant metastases } \\
\hline Distant lymph node + bone + liver + lung & 41 \\
\hline Distant lymph node + bone + brain + liver & 5 \\
\hline Distant lymph node + bone + brain + lung & 6 \\
\hline Distant lymph node + brain + liver + lung & 4 \\
\hline Bone + brain + liver + lung & 10 \\
\hline Five sites of distant metastases & 5 \\
\hline
\end{tabular}

did not receive radiotherapy or their radiotherapy status was unknown, 2028 (63.0\%) received chemotherapy, and the remaining $1190(37.0 \%)$ patients did not receive chemotherapy or their chemotherapy status was unknown. In patients who received esophagectomy, 39 (70.9\%) and $49(89.1 \%)$ patients received radiotherapy (29 patients received radiotherapy prior to surgery, 8 patients underwent radiotherapy after surgery, and 2 patients had radiotherapy before and after surgery) and chemotherapy, respectively. In addition, most of patients $(90.9 \%, 50 / 55)$ who received esophagectomy had a single site of DM, and $54 \%(n=27)$ patients had distant lymph node metastases, followed by lung $(9,18.0 \%)$, liver $(8,16.0 \%)$, bone $(3,6 \%)$, and brain $(3,6 \%)$ metastases.

\section{Survival outcomes and prognostic analysis}

Median OS was 6 and 5 months for patients with a single site of DM and multiple sites of DM, respectively. Median OS for patients with liver, distant lymph node, lung, bone, and brain metastases was $5,10,6,4$, and 6 months, respectively $(p<0.001)$.

In patients with a single site of DM $(\mathrm{n}=1885)$, univariate analysis indicated that age, nodal classification, surgery, radiotherapy, chemotherapy, and site of DM were associated with OS (Table 3). In the entire cohort $(n=3218)$, age, sex, race/ethnicity, tumor location, histological subtype, nodal classification, surgery, radiotherapy, chemotherapy, and the number of DM sites were prognostic factors for OS (Table 3).

Multivariate analysis of patients with a single site of DM revealed that the site of DM was an independent prognostic factor affecting OS (Table 4). Using liver metastases as the reference, DM to bone was associated with poorer OS (hazard ratio [HR] 1.211, 95\% confidence interval [CI] 1.023-1.434, $p=0.026$ ), while DM to distant lymph nodes was associated with better OS (HR 0.829, 95\% CI 0.722-0.953, $p=0.008$ ). Brain (HR 1.077, 95\% CI 0.779-1.490, $p=0.653$ ) and lung (HR 0.865, 95\% CI 0.736-1.018, $p=0.081$ ) metastases were associated with similar OS compared to liver metastases. The corresponding survival curves are shown in Figure 1. In the entire cohort, the number of DM was an independent prognostic factor for OS; multiple sites of DM were associated with poorer OS (HR 1.388, 95\% CI 1.269-1.518, $p<0.001$ ). In addition, surgery, radiotherapy, and chemotherapy were associated with better OS in multivariate prognostic models of patients with single or multiple sites of DM.

We further analyzed the effect of site of DM in patients with a single site of DM stratified by histological subtypes. In esophageal SCC, using liver metastases as the reference, distant lymph node metastases (HR $0.6579,95 \%$ CI 0.503 $0.858, p=0.002$ ) were associated with better OS, while bone (HR 1.151, 95\% CI 0.844-1.569, $p=0.374$ ), brain (HR 0.776, 95\% CI 0.191-3.155, $p=0.723$ ), and lung (HR 0.891, 95\% CI $0.684-1.161, p=0.393)$ metastases were associated with similar OS compared to liver metastases. The corresponding survival curves are shown in Figure 2A. In esophageal AC, using liver metastases as the reference, bone metastases were associated with poorer OS (HR 1.224, 95\% CI 1.024-1.462, $p=0.026$ ), while distant lymph node metastases (HR 0.662 , 95\% CI 0.570-0.768, $p<0.001)$ were associated with better OS. Patients with brain (HR 0.981, 95\% CI 0.728-1.321, $p=0.899$ ) and lung (HR 0.859, 95\% CI 0.698-1.058, $p=0.153$ ) 
Table 3 Univariate Cox regression analysis of prognostic factors for overall survival in stage IV esophageal cancer

\begin{tabular}{|c|c|c|c|c|c|c|}
\hline \multirow[t]{2}{*}{ Variable } & \multicolumn{3}{|c|}{ One site of distant metastases } & \multicolumn{3}{|c|}{ Entire cohort } \\
\hline & HR & $95 \% \mathrm{Cl}$ & $p$-value & HR & $95 \% \mathrm{Cl}$ & $p$-value \\
\hline \multicolumn{7}{|l|}{ Age (years) } \\
\hline$<50$ & I & & & 1 & & \\
\hline$\geq 50$ & 1.222 & $1.011-1.477$ & 0.038 & 1.159 & $1.012-1.328$ & 0.032 \\
\hline \multicolumn{7}{|l|}{ Sex } \\
\hline Male & I & & & $\mathrm{I}$ & & \\
\hline Female & $0.88 I$ & $0.769-1.011$ & 0.070 & 0.883 & $0.794-0.983$ & 0.022 \\
\hline \multicolumn{7}{|l|}{ Race/ethnicity } \\
\hline White & I & & & 1 & & \\
\hline Black & 1.164 & $0.992-1.365$ & 0.062 & $\mathrm{I} .167$ & $1.032-1.319$ & 0.014 \\
\hline Other & 0.866 & $0.685-1.095$ & 0.230 & 0.900 & $0.757-1.069$ & 0.229 \\
\hline \multicolumn{7}{|l|}{ Tumor location } \\
\hline Upper third & 1 & & & I & & \\
\hline Middle third & 0.904 & $0.680-1.203$ & 0.490 & 0.946 & $0.758-1.181$ & 0.623 \\
\hline Lower third & 0.779 & $0.603-1.005$ & 0.055 & 0.794 & $0.65 I-0.968$ & 0.023 \\
\hline Overlapping lesion & 0.913 & $0.662-1.260$ & 0.58 & 1.000 & $0.783-1.278$ & 0.999 \\
\hline \multicolumn{7}{|l|}{ Histology } \\
\hline SCC & I & & & I & & \\
\hline$A C$ & 0.912 & $0.816-1.020$ & 0.106 & 0.886 & $0.814-0.965$ & 0.005 \\
\hline \multicolumn{7}{|l|}{ Grade } \\
\hline GI & 1 & & & 1 & & \\
\hline G2 & 0.856 & $0.624-1.175$ & 0.337 & 0.989 & $0.766-1.276$ & 0.933 \\
\hline G3-4 & 1.086 & $0.796-1.482$ & 0.603 & 1.239 & $0.964-1.592$ & 0.094 \\
\hline \multicolumn{7}{|l|}{ Tumor classification } \\
\hline $\mathrm{TI}-2$ & I & & & I & & \\
\hline T3-4 & 0.918 & $0.808-1.043$ & 0.191 & 0.923 & $0.837-1.018$ & 0.109 \\
\hline \multicolumn{7}{|l|}{ Nodal classification } \\
\hline No & I & & & I & & \\
\hline $\mathrm{NI}$ & 0.788 & $0.701-0.886$ & $<0.001$ & 0.862 & $0.786-0.944$ & 0.001 \\
\hline \multicolumn{7}{|l|}{ Surgery } \\
\hline No & I & & & I & & \\
\hline Yes & 0.316 & $0.213-0.470$ & $<0.001$ & 0.302 & $0.209-0.436$ & $<0.001$ \\
\hline \multicolumn{7}{|l|}{ Radiotherapy } \\
\hline No/unknown & I & & & I & & \\
\hline Yes & 0.672 & $0.607-0.745$ & $<0.001$ & 0.720 & $0.666-0.778$ & $<0.001$ \\
\hline \multicolumn{7}{|l|}{ Chemotherapy } \\
\hline No/unknown & I & & & I & & \\
\hline Yes & 0.288 & $0.259-0.321$ & $<0.001$ & 0.288 & $0.265-0.312$ & $<0.001$ \\
\hline \multicolumn{7}{|l|}{ Metastatic sites } \\
\hline Liver & I & & & - & & \\
\hline Distant lymph node & 0.677 & $0.596-0.770$ & $<0.001$ & - & - & - \\
\hline Bone & 1.228 & I.055-1.429 & 0.008 & - & - & - \\
\hline Brain & 0.964 & $0.721-1.288$ & 0.803 & - & - & - \\
\hline Lung & 0.925 & $0.797-1.074$ & 0.307 & - & - & - \\
\hline \multicolumn{7}{|c|}{ Number of sites of metastases (n) } \\
\hline I & - & & & I & & \\
\hline$>1$ & - & - & - & 1.398 & $1.294-1.510$ & $<0.001$ \\
\hline
\end{tabular}

Note: “-” indicates no data.

Abbreviations: AC, adenocarcinoma; Cl, confidence interval; GI, well differentiated; G2, moderately differentiated; G3, poorly differentiated; G4, undifferentiated; HR, hazard ratio; N, node; SCC, squamous cell carcinoma; $\mathrm{T}$, tumor.

metastases had similar OS compared to patients with liver metastases. The corresponding survival curves are shown in Figure 2B.

\section{Discussion}

This population-based study indicates that the prognosis of patients with metastatic EC differs according to the site of 
Table 4 Multivariate Cox regression analysis of prognostic factors for overall survival in stage IV esophageal cancer

\begin{tabular}{|c|c|c|c|c|c|c|}
\hline \multirow[t]{2}{*}{ Variable } & \multicolumn{3}{|c|}{ One site of distant metastases } & \multicolumn{3}{|c|}{ Entire cohort } \\
\hline & $\overline{H R}$ & $95 \% \mathrm{Cl}$ & $p$-value & HR & $95 \% \mathrm{Cl}$ & $p$-value \\
\hline \multicolumn{7}{|l|}{ Age (years) } \\
\hline$<50$ & 1 & & & I & & \\
\hline$\geq 50$ & 1.063 & $0.866-1.306$ & 0.558 & 1.110 & $0.947-1.30 \mid$ & 0.196 \\
\hline \multicolumn{7}{|l|}{ Sex } \\
\hline Male & - & & & I & & \\
\hline Female & - & - & - & 0.854 & $0.752-0.969$ & 0.015 \\
\hline \multicolumn{7}{|l|}{ Race/ethnicity } \\
\hline White & - & & & I & & \\
\hline Black & - & - & - & 1.060 & $0.905-1.242$ & 0.470 \\
\hline Other & - & - & - & 0.861 & $0.698-1.062$ & 0.161 \\
\hline \multicolumn{7}{|l|}{ Tumor location } \\
\hline Upper third & - & & & 1 & & \\
\hline Middle third & - & - & - & 1.012 & $0.797-1.286$ & 0.921 \\
\hline Lower third & - & - & - & 0.934 & $0.743-1.173$ & 0.555 \\
\hline Overlapping lesion & - & - & - & 1.093 & $0.835-1.430$ & 0.518 \\
\hline \multicolumn{7}{|l|}{ Histology } \\
\hline SCC & - & & & I & & \\
\hline$A C$ & - & - & - & 0.883 & $0.797-0.979$ & 0.018 \\
\hline \multicolumn{7}{|l|}{ Nodal classification } \\
\hline No & I & & & 1 & & \\
\hline $\mathrm{NI}$ & 0.973 & $0.860-1.100$ & 0.658 & 0.946 & $0.856-1.046$ & 0.280 \\
\hline \multicolumn{7}{|l|}{ Surgery } \\
\hline No & 1 & & & I & & \\
\hline Yes & 0.449 & $0.30 \mathrm{I}-0.669$ & $<0.001$ & 0.465 & $0.317-0.683$ & $<0.001$ \\
\hline \multicolumn{7}{|l|}{ Radiotherapy } \\
\hline No/unknown & I & & & I & & \\
\hline Yes & 0.798 & $0.712-0.896$ & $<0.001$ & 0.833 & $0.761-0.912$ & $<0.001$ \\
\hline \multicolumn{7}{|l|}{ Chemotherapy } \\
\hline No/unknown & I & & & I & & \\
\hline Yes & 0.315 & $0.280-0.355$ & $<0.001$ & 0.297 & $0.270-0.326$ & $<0.001$ \\
\hline \multicolumn{7}{|l|}{ Metastatic sites } \\
\hline Liver & I & & & - & & \\
\hline Distant lymph node & 0.829 & $0.722-0.953$ & 0.008 & - & - & - \\
\hline Bone & 1.211 & I.023-1.434 & 0.026 & - & - & - \\
\hline Brain & 1.077 & $0.779-1.490$ & 0.653 & - & - & - \\
\hline Lung & 0.865 & $0.736-1.018$ & 0.081 & - & - & - \\
\hline \multicolumn{7}{|c|}{ Number of sites of metastases (n) } \\
\hline I & - & & & I & & \\
\hline$>1$ & - & - & & 1.388 & $1.269-1.518$ & $<0.001$ \\
\hline
\end{tabular}

Note: “-” indicates no data.

Abbreviations: $\mathrm{AC}$, adenocarcinoma; $\mathrm{Cl}$, confidence interval; $\mathrm{HR}$, hazard ratio; $\mathrm{N}$, node; SCC, squamous cell carcinoma.

$\mathrm{DM}$, and also that multimodality treatment may improve OS in metastatic EC.

Similarly to previous retrospective reports and autopsy studies of patients with metastatic EC, ${ }^{12-15}$ the most common sites of DM in this study were the liver, followed by distant lymph nodes, lung, bone, and brain. Notably, this study was based on a much larger sample size than the previous studies. Moreover, our analysis provides additional information on the prognostic impact of site-specific DM in metastatic EC.

There are limited studies on the effect of the site of DM on survival in metastatic EC. Chen et al found that DM (not including DM to distant lymph nodes) was not associated with OS in metastatic esophageal SCC. ${ }^{13}$ Tanaka et al also observed no significant difference in median survival for different sites of DM, including liver, bone, and lung ( $p=0.8786) .{ }^{10}$ The study by Blank et al included patients with metastatic esophagogastric $\mathrm{AC}$, and found that localization (distant hematogenous vs. peritoneal carcinomatosis vs. distant lymph nodes, $p=0.631)$ and the number $(p=0.754)$ of metastases were not significant prognostic factors for survival; ${ }^{18}$ however, they did not further analyze the effect of site-specific DM on survival. In this study, patients with 
distant lymph node metastases had better OS than patients with liver metastases, while bone metastases were associated with poorer OS compared to liver metastases, especially in esophageal AC. We also observed similar OS rates for patients with liver, bone, or lung metastases in esophageal SCC. Therefore, patients with stage IV EC represent a heterogeneous group that could potentially be classified by sitespecific metastasis. In addition, the number of DM was also

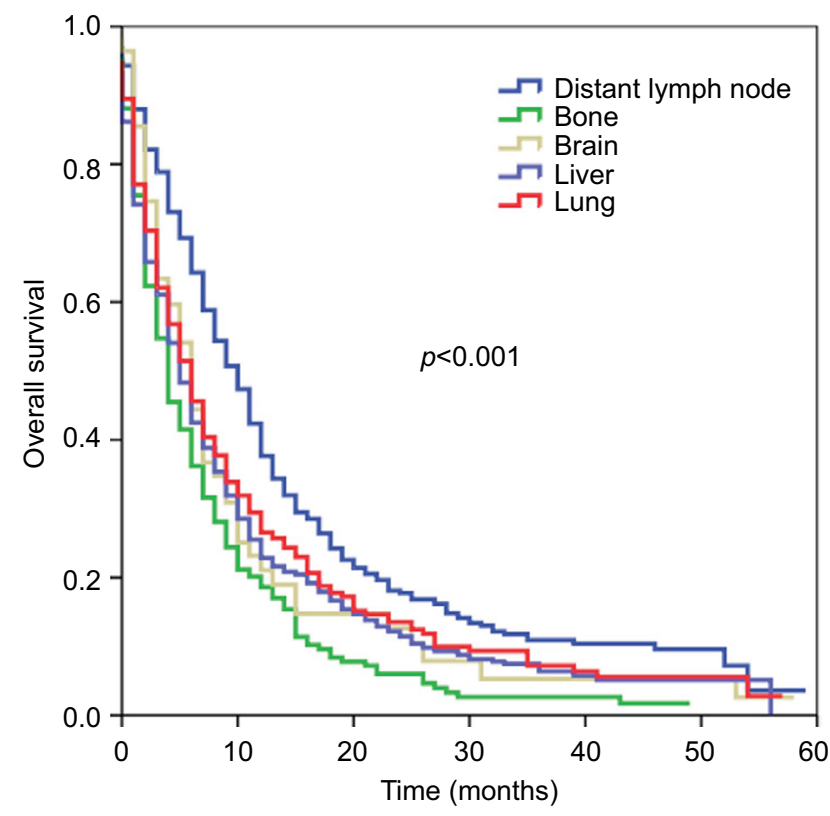

Figure I Kaplan-Meier survival curves for patients with metastatic esophageal cancer stratified by sites of distant metastases.

A

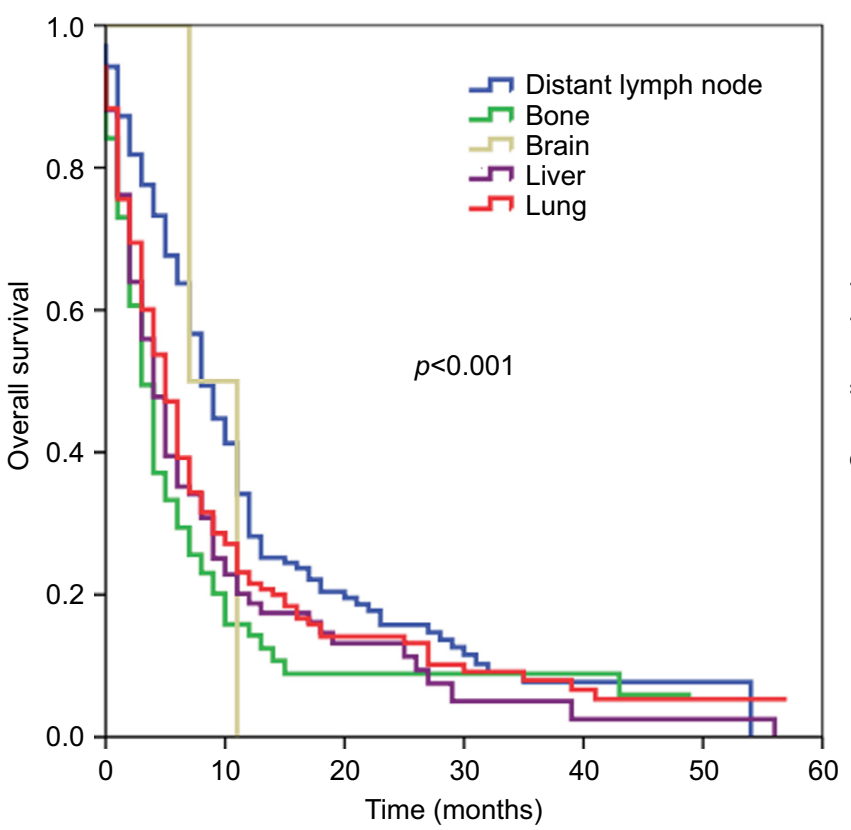

an independent prognostic factor for OS. These observations may help physicians more accurately assess the prognosis of patients with metastatic EC.

In this study, patients with distant lymph node metastases had significantly longer OS (median, 10 months) than patients with DM to other sites. Chao et al reported a similar median OS duration of 14.2 months for patients with non-regional lymph node metastases after chemoradiotherapy. ${ }^{19}$ Therefore, combined modality treatment may yield reasonable survival outcomes for patients with EC who have distant lymph node metastases.

In breast cancer, patients with bone metastases achieve significantly better survival than patients with metastasis to other sites. ${ }^{20,21}$ However, in this study, patients with bone metastases had significantly poorer OS (median, 4 months) than those with metastasis to other sites. Bone metastases were also associated with poor survival in a population-based study of metastatic lung cancer. ${ }^{22}$ The mechanism by which bone metastases lead to poorer survival compared to other sites of DM in metastatic EC is not known. Overexpression of parathyroid hormone-related protein (PTHrP) is associated with increased risk of bone metastases in small cell lung cancer. ${ }^{23}$ Osteolytic bone metastases often overproduce PTHrP. ${ }^{1}$ Bone metastases in EC was associated with humoral hypercalcemia and leukocytosis, which may promote rapid disease progression. ${ }^{24-26}$

There is no consensus on whether palliative radiotherapy or surgery is of value in metastatic EC. Several retrospective and prospective studies have suggested that palliative

B

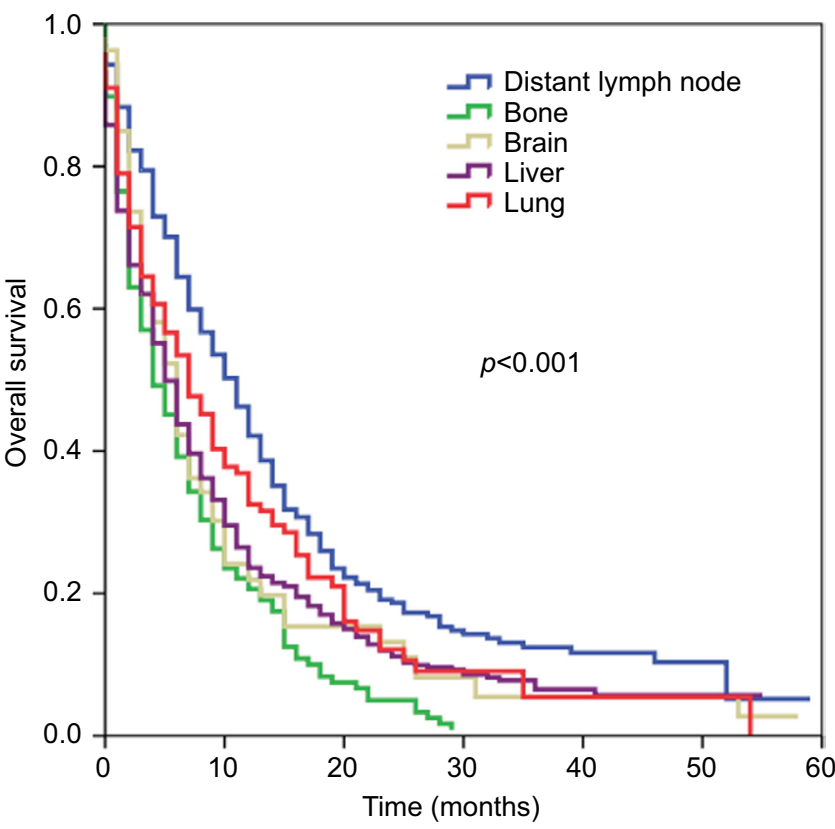

Figure 2 Kaplan-Meier survival curves for patients with metastatic esophageal squamous cell carcinoma (A) and adenocarcinoma (B) stratified by sites of distant metastases. 
radiotherapy could improve survival in metastatic EC. ${ }^{27-29}$ In addition, several recent retrospective studies found that resection of primary tumors may be considered for a select group of patients with stage IV EC who achieve a favorable response to systemic chemotherapy. ${ }^{18,19,30}$ Our previous study of the SEER database also found that surgery and preoperative radiotherapy were associated with better survival in metastatic EC. ${ }^{11}$ Furthermore, lymph node dissection is associated with better survival. ${ }^{31}$ In the present study, most of patients who underwent esophagectomy also received radiotherapy and chemotherapy, and surgery. Radiotherapy and chemotherapy were independent favorable prognostic factors for OS, similarly to results in metastatic breast cancer, colorectal cancer, and renal cell carcinoma. ${ }^{32-36}$ However, the numbers of patients who underwent surgical resection of the primary tumor in the aforementioned studies were not large enough to reach definite conclusions. In addition, these retrospective studies possess methodological defects. Therefore, further studies are required to identify the subgroups of patients who may benefit from aggressive multimodality therapy.

We should acknowledge that this study has several limitations. First, retrospective analyses may be inherently biased. Second, the SEER database lacks detailed information on comorbidities, which could lead to potential selection bias towards patients receiving a specific treatment. In addition, the SEER program only included five site-specific DM at the initial diagnosis, and we could not obtain further details concerning the other sites of DM. Third, the findings of this study can only be generalized to the United States population and are not representative of the global population, especially in endemic areas such as People's Republic of China. Moreover, the overall sensitivity of the radiotherapy and chemotherapy data in the current SEER database was $80 \%$ and $68 \%$, respectively. However, the radiotherapy and chemotherapy data had a high specificity. ${ }^{17}$

\section{Conclusion}

In conclusion, in advanced EC, patients with bone metastases seem to have the poorest OS, while patients with distant lymph node metastases have the best OS. This study suggests that increased attention should be paid to the mechanisms and prognostic value of site-specific metastases. Furthermore, additional studies are required to identify the subset(s) of patients with advanced EC who may benefit from primary local treatment.

\section{Disclosure}

The authors report no conflicts of interest in this work.

\section{References}

1. Langley RR, Fidler IJ. Tumor cell-organ microenvironment interactions in the pathogenesis of cancer metastasis. Endocr Rev. 2007;28(3):297-321.

2. Langley RR, Fidler IJ. The seed and soil hypothesis revisited - the role of tumor-stroma interactions in metastasis to different organs. Int J Cancer. 2011;128(11):2527-2535.

3. Chen LL, Blumm N, Christakis NA, Barabási AL, Deisboeck TS. Cancer metastasis networks and the prediction of progression patterns. $\mathrm{Br} J$ Cancer. 2009;101(5):749-758.

4. Kakiuchi S, Daigo Y, Tsunoda T, Yano S, Sone S, Nakamura Y. Genomewide analysis of organ-preferential metastasis of human small cell lung cancer in mice. Mol Cancer Res. 2003;1(7):485-499.

5. Arnold M, Soerjomataram I, Ferlay J, Forman D. Global incidence of oesophageal cancer by histological subtype in 2012. Gut. 2015;64(3):381-387.

6. Brown LM, Devesa SS. Epidemiologic trends in esophageal and gastric cancer in the United States. Surg Oncol Clin NAm. 2002;11(2):235-256.

7. Rubenstein JH, Shaheen NJ. Epidemiology, diagnosis, and management of esophageal adenocarcinoma. Gastroenterology. 2015;149(2): 302-317.e1.

8. Enzinger PC, Mayer RJ. Esophageal cancer. $N$ Engl J Med. 2003; 349(23):2241-2252.

9. Horner MJ, Ries LAG, Krapcho M, et al, editors. SEER Cancer Statistics Review, 1975-2006. Bethesda, MD: National Cancer Institute; 2009. Available from: http://seer.cancer.gov/csr/1975_2006/. Accessed May 10, 2017.

10. Tanaka T, Fujita H, Matono S, et al. Outcomes of multimodality therapy for stage IVB esophageal cancer with distant organ metastasis (M1-Org). Dis Esophagus. 2010;23(8):646-651.

11. Wu SG, Xie WH, Zhang ZQ, et al. Surgery combined with radiotherapy improved survival in metastatic esophageal cancer in a surveillance epidemiology and end results population-based study. Sci Rep. 2016;6:28280

12. Bosch A, Frias Z, Caldwell WL, Jaeschke WH. Autopsy findings in carcinoma of the esophagus. Acta Radiol Oncol Radiat Phys Biol. 1979;18(2):103-112.

13. Chen MQ, Xu BH, Zhang YY. Analysis of prognostic factors for esophageal squamous cell carcinoma with distant organ metastasis at initial diagnosis. J Chin Med Assoc. 2014;77(11):562-566.

14. Tustumi F, Kimura CM, Takeda FR, Sallum RA, Ribeiro-Junior U, Cecconello I. [Evaluation of lymphatic spread, visceral metastasis and tumoral local invasion in esophageal carcinomas]. Arq Bras Cir Dig. 2016;29(4):215-217. Portuguese [with English abstract].

15. Mariette C, Balon JM, Piessen G, Fabre S, Van Seuningen I, Triboulet JP. Pattern of recurrence following complete resection of esophageal carcinoma and factors predictive of recurrent disease. Cancer. 2003;97(7):1616-1623.

16. Surveillance, Epidemiology, and End Results (SEER) Program. SEER*Stat database: incidence - SEER 18 Regs research data + Hurricane Katrina impacted Louisiana cases, Nov 2016 Sub (1973-2014 varying) - linked to county attributes - Total U.S., 1969-2015 counties. National Cancer Institute, DCCPS, Surveillance Research Program, Surveillance Systems Branch, released April 2017, based on the November 2016 submission.

17. Noone AM, Lund JL, Mariotto A, et al. Comparison of SEER treatment data with Medicare claims. Med Care. 2016;54(9):e55-e64.

18. Blank S, Lordick F, Dobritz M, et al. A reliable risk score for stage IV esophagogastric cancer. Eur J Surg Oncol. 2013;39(8): 823-830.

19. Chao YK, Wu YC, Liu YH, et al. Distant nodal metastases from intrathoracic esophageal squamous cell carcinoma: characteristics of long-term survivors after chemoradiotherapy. JSurg Oncol. 2010;102(2):158-162.

20. Wu SG, Li H, Tang LY, et al. The effect of distant metastases sites on survival in de novo stage-IV breast cancer: a SEER database analysis. Tumour Biol. 2017;39(6):1010428317705082. 
21. Hölzel D, Eckel R, Bauerfeind I, et al. Survival of de novo stage IV breast cancer patients over three decades. J Cancer Res Clin Oncol. 2017;143(3):509-519.

22. Riihimäki M, Hemminki A, Fallah M, et al. Metastatic sites and survival in lung cancer. Lung Cancer. 2014;86(1):78-84.

23. Miki T, Yano S, Hanibuchi M, Kanematsu T, Muguruma H, Sone S. Parathyroid hormone-related protein (PTHrP) is responsible for production of bone metastasis, but not visceral metastasis, by human small cell lung cancer SBC-5 cells in natural killer cell-depleted SCID mice. Int J Cancer. 2004;108(4):511-515.

24. Watanabe HA, Matsushita H, Matsui H, et al. Esophageal carcinoma with high serum parathyroid hormone-related protein (PTHrP) level. J Gastroenterol. 1999;34(4):510-515.

25. Deans C, Wigmore S, Paterson-Brown S, Black J, Ross J, Fearon KC. Serum parathyroid hormone-related peptide is associated with systemic inflammation and adverse prognosis in gastroesophageal carcinoma. Cancer. 2005;103(9):1810-1818.

26. Tachimori Y, Watanabe H, Kato H, et al. Hypercalcemia in patients with esophageal carcinoma. The pathophysiologic role of parathyroid hormone-related protein. Cancer. 1991;68(12):2625-2629.

27. Hingorani M, Dixit S, Johnson M, et al. Palliative radiotherapy in the presence of well-controlled metastatic disease after initial chemotherapy may prolong survival in patients with metastatic esophageal and gastric cancer. Cancer Res Treat. 2015;47(4):706-717.

28. Li T, Lv J, Li F, et al. Prospective randomized phase II study of concurrent chemoradiotherapy versus chemotherapy alone in stage IV esophageal squamous cell carcinoma. J Clin Oncol. 2016;34(Suppl 15):4050.
29. Guttmann DM, Mitra N, Bekelman J, et al. Improved overall survival with aggressive primary tumor radiotherapy for patients with metastatic esophageal cancer. J Thorac Oncol. 2017;12(7):1131-1142.

30. Wang J, Suri JS, Allen PK, et al. Factors predictive of improved outcomes with multimodality local therapy after palliative chemotherapy for stage IV esophageal cancer. Am J Clin Oncol. 2016;39(3):228-235.

31. Wu SG, He ZY, Wang Y, et al. Lymph node dissection improved survival in patients with metastatic thoracic esophageal cancer: an analysis of 220 patients from the SEER database. Int J Surg. 2016;35:13-18.

32. Wu SG, Zhang WW, Sun JY, et al. The survival benefits of local surgery in stage IV breast cancer are not affected by breast cancer subtypes: a population-based analysis. Oncotarget. 2017;8(40):67851-67860.

33. Le Scodan R, Stevens D, Brain E, et al. Breast cancer with synchronous metastases: survival impact of exclusive locoregional radiotherapy. J Clin Oncol. 2009;27(9):1375-1381.

34. Warschkow R, Güller U, Tarantino I, et al. Improved survival after primary tumor surgery in metastatic breast cancer: a propensity-adjusted, population-based SEER trend analysis. Ann Surg. 2016;263(6): 1188-1198.

35. Heng DY, Wells JC, Rini BI, et al. Cytoreductive nephrectomy in patients with synchronous metastases from renal cell carcinoma: results from the International Metastatic Renal Cell Carcinoma Database Consortium. Eur Urol. 2014;66(4):704-710.

36. Zhang XL, Liu RF, Zhang D, Zhang YS, Wang T. Laparoscopic versus open liver resection for colorectal liver metastases: a systematic review and meta-analysis of studies with propensity score-based analysis. Int J Surg. 2017;44:191-203.
Cancer Management and Research

\section{Publish your work in this journal}

Cancer Management and Research is an international, peer-reviewed open access journal focusing on cancer research and the optimal use of preventative and integrated treatment interventions to achieve improved outcomes, enhanced survival and quality of life for the cancer patient. The manuscript management system is completely online and includes

\section{Dovepress}

a very quick and fair peer-review system, which is all easy to use. Visi http://www.dovepress.com/testimonials.php to read real quotes from published authors. 